Proof to: Shunji Kinoshita

Department of Chemistry

Konan University

Okamoto 8-9-1, Higashinada-ku

Kobe 658-8501, Japan

e-mail: s-kino@center.konan-u.ac.jp

tel: +81-78-435-2563

fax: +81-78-435-2539

\title{
Additive Effect of Ionic Liquids on the Electrochemical Property of a Sulfur Composite Electrode for All-Solid-State Lithium-Sulfur Battery
}

Shunji Kinoshita, Kazuya Okuda, Nobuya Machida, and Toshihiko Shigematsu

Department of Chemistry, Konan University, Okamoto 8-9-1, Higashinada-ku, Kobe 658-8501, Japan

E-mail: s-kino@center.konan-u.ac.jp 


\section{Abstract}

We investigated additive effect of five kinds of ionic liquids, such as 1-ethyl-3-methyl-imidazolium bis(trifluoromethane-sulfonyl)imide [EMI][TFSI], 1-ethyl-3-methylimidazolium tetrafluoroborate [EMI][BF $]$ ], 1-buthyl-3-methyl-imidazolium bis(trifluoromethanesulfonyl) imide [BMI][TFSI], 1-buthyl-3-methyl-imidazolium tetrafluoroborate [BMI][BF 4 , and/or 1-buthyl-3-methyl-imidazolium iodide [BMI][I], on electrochemical properties of the sulfur composite electrode for all-solid-state lithium-sulfur batteries. The sulfur composite electrode that was composed of sulfur (29.9 wt\%), vapor-grown carbon fiber (VGCF, $9.9 \mathrm{wt} \%$ ), solid electrolyte (amorphous $\mathrm{Li}_{3} \mathrm{PS}_{4}, 60.0 \mathrm{wt} \%$ ), and [EMI][TFSI] (0.2 wt\%) showed high initial specific capacity of $1270 \mathrm{mAhg}^{-1}$ at $25^{\circ} \mathrm{C}$, which was calculated on the base of the weight of sulfur. To construct a laboratory-scale all-solid-state battery, amorphous $\mathrm{Li}_{3} \mathrm{PS}_{4}$ and meta-stable $\mathrm{Li}_{4.4} \mathrm{Si}$ alloy were used as solid electrolyte and as negative electrode materials, respectively. The laboratory-scale all-solid-state battery showed good discharge-charge cycle performance under a constant current density of $0.1 \mathrm{mAcm}^{-2}\left(24 \mathrm{mAg}^{-1}\right)$ at room temperature and retained the large specific capacity more than $1230 \mathrm{mAhg}^{-1}$ even after 50 cycles at $25^{\circ} \mathrm{C}$. The capacity after 50 cycles was about $97 \%$ of the initial capacity of the test cell.

Keywords: sulfur, ionic liquid, solid electrolytes, lithium battery, all-solid-state battery 


\section{Introduction}

Recently large-scale lithium-ion batteries have been attracted much attention, because they are key energy storage devices for electric vehicles and stationary load-leveling systems. Lithium-sulfur(Li-S) battery is one of the most promising devices for the next-generation energy storages[1-6], because elemental sulfur has a large theoretical specific capacity of $1675 \mathrm{mAhg}^{-1}$, which is five times larger than that of conventional cathode materials such as $\mathrm{LiCoO}_{2}$, $\mathrm{LiNi}_{1 / 3} \mathrm{Mn}_{1 / 3} \mathrm{Co}_{1 / 3} \mathrm{O}_{2}$, and so on $[7,8]$. The capacity of the Li-S battery with conventional electrolyte solution, however, rapidly fades away on discharge-charge cycling. The capacity fading is attributed to the facts that the reduction of sulfur produces several lithium poly-sulfides $\left(\mathrm{Li}_{2} \mathrm{~S}_{\mathrm{x}}\right)$ in the battery and that the poly-sulfides dissolve into the electrolyte solution. The dissolution of lithium poly-sulfides is known to be the main reason for low charging efficiency and large self-discharge fraction of the Li-S batteries with conventional electrolyte solutions [3, 9-11].

On the other hand, in the all-solid-state lithium-sulfur batteries with inorganic solid electrolytes, elemental sulfur is expected to work effectively as positive electrode materials [12-17], because the inorganic solid electrolytes are used as a separator in the all-solid-state batteries and lithium poly-sulfides, which are produced during discharge process of the Li-S batteries, do not dissolve in the solid electrolytes. Consequently, the discharge-charge capacity should be maintained for the all-solid-state batteries with inorganic solid electrolytes during discharge-charge cycling. Then, the all-solid-state lithium-sulfur battery is expected to show good discharge-charge performance with large specific capacity. 
The discharge-charge reactions of the all-solid-state battery progress in the interfacial regions between active materials and solid electrolytes. Then the uniform dispersions of the active materials, electronic and ionic conductive materials in the composite electrodes are important factor to achieve good performance of the all-solid-state batteries. We recently reported the electrochemical properties of the all-solid-state Li-S battery with the composite electrode of sulfur, VGCF (vapor grown carbon fiber), and amorphous $\mathrm{Li}_{3} \mathrm{PS}_{4}$ (solid electrolyte) as positive electrode materials [18]. The amorphous $\mathrm{Li}_{3} \mathrm{PS}_{4}$ was used as a solid electrolyte which showed high lithium-ion conductivity $2 \times 10^{-4} \mathrm{Scm}^{-1}$ at room temperature $[19,20]$. The composite as positive electrode materials was prepared by use of a high-energy ball-milling process [18]. The laboratory-scale all-solid-state test cell with the composite electrode showed a large specific capacity more than $1300 \mathrm{mAhg}^{-1}$, which was calculated on the base of sulfur weight. In the previous paper [18], we also showed that the discharge capacity of the composite was remarkably affected by the mixing conditions to prepare the composite of sulfur, VGCF and a- $\mathrm{Li}_{3} \mathrm{PS}_{4}$. In order to achieve good discharge-charge performance, the high-energy ball-milling treatment longer than $20 \mathrm{~h}$ on the composite was needed. This result suggests that adequate contacts among the active materials sulfur, electronic conductor VGCF, and a solid electrolyte a- $\mathrm{Li}_{3} \mathrm{PS}_{4}$ are necessary to realize good electrochemical performance of the composite electrode for all-solid-sate batteries.

There are other works on composite electrodes of sulfur and carbon for all-solid-state lithium-sulfur batteries [21, 22]. Nagao et al. examined the electrochemical properties of the sulfur-acetylene black composites that were prepared by use of a high-energy ball-milling process 
[19]. They reported that the composite ball-milled at $155^{\circ} \mathrm{C}$ showed large reversible capacities more than $1000 \mathrm{mAhg}^{-1}$ and good discharge-charge cycle performance. However, the composite prepared at room temperature showed only $500 \mathrm{mAhg}^{-1}$ and poor reversibility [23]. They also suggested that uniform distributions and contacts among active materials, carbon materials, and solid electrolytes in the composite electrode were the important factor to obtain high specific capacities of the all-solid-state lithium-sulfur batteries.

In order to achieve the uniform distributions in the composite electrode, we expect that the addition of liquid components to the composite electrode would be effective and should improve its electrochemical performance, because the liquid components would be helpful to attain uniform dispersions of the active materials, carbon materials, and solid electrolytes in the composite. Ionic liquids are in a liquid phase at room temperature and are also called room temperature molten salts. The ionic liquids have some characteristic physical and chemical properties such as non-flammability, high polarity, low vapor pressure, and so on [24-27]. There are some reports on lithium-ion batteries using the ionic liquids as electrolytes instead of conventional electrolyte solutions [28-34]. Jun-Woo et al. reported the fabrication and properties of a Li-S battery using the ionic liquid Li[TFSA]-[DEME][TFSA] (lithium bis(trifluoromethane-sulfonyl)amide- $\mathrm{N}, \mathrm{N}-$ diethyl-N-methyl-N-(2-methoxy-ethyl)ammonium bis(trifluoromethane-sulfonyl)amide) [35].

The Li-S battery with the ionic liquid showed a large discharge capacity of $800 \mathrm{mAhg}^{-1}$ and good discharge-charge cycle performance [35].

Hence, we suppose that the addition of the ionic liquids to the sulfur composite electrode should 
be helpful to attain uniform dispersions of the active materials, carbon materials, and solid electrolytes in the composite electrode and should also improve the utilization of the sulfur composite electrode for all-solid-state Li-S batteries. Then we try to add several kinds of ionic liquids to the sulfur composite electrode to improve the electrochemical properties of all-solid-state Li-S battery with sulfide-based solid electrolytes. In this study, we attempt to prepare the sulfur-VGCF- $\mathrm{Li}_{3} \mathrm{PS}_{4}$ composites which were added several kinds of ionic liquids and investigate electrochemical properties of the obtained composites as positive electrode materials for all-solid-state Li-S batteries.

\section{Experimental}

\subsection{Preparation of sulfur composites containing ionic liquids}

We used five kinds of ionic liquids, such as 1-ethyl-3-methyl-imidazolium bis(trifluoromethane-sulfonyl)imide [EMI][TFSI], 1-ethyl-3-methyl-imidazolium tetrafluoroborate [EMI][BF 4 ], 1-buthyl-3-methyl-imidazolium bis(trifluoromethane-sulfonyl) imide [BMI][TFSI], 1-buthyl-3-methyl-imidazolium tetrafluoroborate [BMI][BF 4 , and / or 1-buthyl-3-methylimidazolium iodide [BMI][I], as additives to the sulfur composites in order to improve the dispersibility of the composites for positive electrode materials. Those ionic liquids were purchased from Tokyo Chemical Industry Co. Ltd., and were used as received. Elemental sulfur (Wako Pure Chemical Industries Ltd., 99 \%), VGCF (vapor-grown carbon fiber, Showa Denko) and amorphous $\mathrm{Li}_{3} \mathrm{PS}_{4}$ were used as starting materials to prepare the composites for positive electrode 
materials. The a- $\mathrm{Li}_{3} \mathrm{PS}_{4}$ was used as solid electrolyte in this study and was prepared from the raw materials $\mathrm{Li}_{2} \mathrm{~S}$ (Nippon Chemical Industrial Co. Ltd., $99 \%$ ) and $\mathrm{P}_{2} \mathrm{~S}_{5}$ (Sigma-Ardrich Co. Ltd., $99 \%$ ) by use of a high-energy ball-milling process. The detailed preparation procedure of the electrolyte was described elsewhere [19, 20, 36].

Fig. 1 shows a schematic diagram of the preparation process of the composites composed of sulfur, VGCF, a- $\mathrm{Li}_{3} \mathrm{PS}_{4}$ and ionic liquid. The desired amounts of the starting materials sulfur (75 wt\%) and VGCF (25 wt\%) were weighed and mixed in an agate mortar. The mixture was placed into a stainless-steel vial (SUS-316) with zirconia balls (seven balls of $10 \mathrm{~mm}$ diameter and ten balls of $3 \mathrm{~mm}$ diameter) and the vial was sealed with an O-ring. The total mass of the mixture was $1.0 \mathrm{~g}$. The vial was set in a planetary ball-milling apparatus (Fritsch GmbH, P-7). The mixture was ball-milled with a rotation rate $380 \mathrm{rpm}$ for $10 \mathrm{~h}$ at room temperature.

The desired amount of the ionic liquid was dissolved in $30 \mathrm{~mL}$ dehydrated acetone. The ball-milled sulfur-VGCF composite was placed in a short-neck flask and the acetone solution containing the ionic liquid was poured into the flask. The sulfur-VGCF composite was thoroughly mixed with the acetone solution under ultrasonic irradiation for $30 \mathrm{~min}$ at room temperature. The solvent was distilled off under reduced pressure at $40{ }^{\circ} \mathrm{C}$ by using a rotatory evaporator, and the residual powder was obtained as a sulfur-VGCF composite containing the ionic liquid. The obtained sulfur-VGCF composite containing the ionic liquid was called an intermediate composite in this study.

The intermediate composite (40 wt\%) and amorphous $\mathrm{Li}_{3} \mathrm{PS}_{4}(60 \mathrm{wt} \%$ ) were mixed in an agate 
mortar. The mixture was placed in a stainless-steel vial with zirconia balls (seven balls of $10 \mathrm{~mm}$ diameter and ten balls of $3 \mathrm{~mm}$ diameter) and the vial was sealed with an O-ring. The mechanical milling of the mixture was conducted by use of a high-energy planetary ball mill apparatus (Fritsch, P-7) with a rotation rate of $380 \mathrm{rpm}$ for $10 \mathrm{~h}$ at room temperature. Then the final composite sample was obtained. Table 1 showed the weight ratios of sulfur, VGCF, solid electrolyte and ionic liquids in the obtained final composites. Those preparation procedures were conducted in a glove box filled with dry Ar gas. The morphology of the obtained composites with and without ionic liquid was evaluated by scanning electron microscope (JEOL, JML-6340F).

\subsection{Electrochemical measurements}

In order to investigate electrochemical properties of the obtained composite samples, a laboratory-scale all-solid-state test cell was fabricated as follows. The obtained final composite powder as a positive electrode and the amorphous $\mathrm{Li}_{3} \mathrm{PS}_{4}$ powder as a solid electrolyte were placed in a poly-ethylene tube of $10 \mathrm{~mm}$ diameter and pressed together under $380 \mathrm{MPa}$, and then meta-stable $\mathrm{Li}_{4.4} \mathrm{Si}$ alloy powder as a negative electrode was pressed on the pellet under $100 \mathrm{MPa}$. The meta-stable $\mathrm{Li}_{4.4} \mathrm{Si}$ alloy was also prepared by using a high-energy ball-milling process $[37,38]$. After releasing the pressure, the obtained three-layered pellet was sandwiched by two stainless-steel rods as current collectors. The loadings of the sulfur-VGCF-Li $\mathrm{LPS}_{4}$-ionic liquid composite and of the $\mathrm{Li}_{4.4} \mathrm{Si}$ alloy in the test cell were $14.3 \mathrm{mgcm}^{-2}$ and $19.1 \mathrm{mgcm}^{-2}$, respectively. The fabrication of the test cell was conducted in a glove box filled with dry Ar gas. 
Galvanostatic discharge-charge experiments for the test cell were performed under a constant current density of $0.1 \mathrm{mAcm}^{-2}\left(24 \mathrm{~mA} \mathrm{~g}^{-1}\right)$ at $25^{\circ} \mathrm{C}$ and $50{ }^{\circ} \mathrm{C}$ in the cut-off voltage range of 1.0 to 2.6 V by the use of a battery tester (Nagano Co. Ltd., BTS-2004H). The impedance of the test cells was measured using a frequency response analyzer (1255B, Solatron Analytical) and potentiostat (1287, Solatron Analytical) at a frequency of $0.01 \mathrm{~Hz}$. The impedance was measured for the test cells after charging up to $2.6 \mathrm{~V}$ at $50{ }^{\circ} \mathrm{C}$.

\section{Results and Discussion}

\subsection{Properties of the intermediate composites composed of sulfur, VGCF, and ionic liquids}

The intermediate composite containing sulfur, VGCF and ionic liquid was obtained as quasi-dry powder. The powder was possible to be pressed into a pellet and any liquid phase did not ooze out from the pellet during the pressing. Figure 2 shows the photographs of the intermediate composite powder containing [EMI][TFSI] and of a pellet obtained from the composite powder. The [EMI][TFSI] mass fraction to the weight of the intermediate composite powder is $5.0 \mathrm{wt} \%$. (For the sample, the [EMI][TFSI] mass fraction to the total weight of the final composite composed of sulfur, VGCF, [EMI][TFSI] and a- $\mathrm{Li}_{3} \mathrm{PS}_{4}$ is $2.0 \mathrm{wt} \%$.) The photographs of the intermediate composite without ionic liquids are also shown in the figure for comparison. There is no difference in the outward appearances between the composites with and without the ionic liquid [EMI][TFSI]. The outward appearance of the intermediate composite was changed with the [EMI][TFSI] contents. The intermediate composite containing more than $15 \mathrm{wt} \%$ [EMI][TFSI] 
showed a thick slurry-like appearance and somewhat sticky character. The intermediate composites containing the ionic liquid less than $10 \mathrm{wt} \%$ can be handled as "dry powders", however the composite containing the ionic liquid more than $15 \mathrm{wt} \%$ could not treated as powder. Then we investigated the intermediate composite containing the ionic liquid less than $10 \mathrm{wt} \%$ in this study.

Figure 3 shows the SEM images of the composites with and without [EMI][TFSI]. The Fig. 3(a) and (b) show SEM images of the composite without [EMI][TFSI]. The composite without [EMI][TFSI] is composed of aggregated particles with about $300 \mathrm{~nm}$ in diameter. The composite has many small voids, which are observed in Fig. 3 (b).

On the other hand, the SEM images of the composite with $0.4 \mathrm{wt} \%$ [EMI][TFSI] are shown in Fig. 3 (c) and (d). The composite with $0.4 \mathrm{wt} \%$ [EMI][TFSI] is composed of large grains which are in 2 to $5 \mu \mathrm{m}$ in diameter and has smooth surfaces. The number of the small voids, which are observed in the composite without [EMI][TFSI], is decreased in the composite with [EMI][TFSI]. The large grains would be composed of sulfur, solid electrolyte, and VGCF. However, those particles could not be distinguished in the SEM observation and also in EDS analysis. Then, the composite with [EMI][TFSI] would have larger good contact area between sulfur and solid electrolyte particles than the composite without the ionic liquid. The increasing of the good contact area should improve the electrochemical capacity of the composite. The particle size and surface state of the composites with the [EMI][TFSI] in the composition range of 0.2 to $2.0 \mathrm{wt} \%$ are almost same. 


\subsection{Electrochemical Properties of the final sulfur-composites at room temperature}

The intermediate composite (40 wt\%) was mixed with a- $\mathrm{Li}_{3} \mathrm{PS}_{4}(60 \mathrm{wt} \%)$, and the mixture was ball-milled to prepare the final composite sample. We investigated the electrochemical properties of the final composite sample by using a laboratory scale all-solid-state test cell. Figure 4 shows the first discharge-charge curves of those test cells in which the final composites containing the five kinds of ionic liquids, [EMI][TFSI](Fig. 4 (b)), [EMI][BF 4 (Fig. 4 (c)), [BMI][TFSI](Fig. 4 (d)), [BMI][BF 4 (Fig. 4 (e)), and [BMI][I](Fig. 4 (f)) are used as positive electrode materials. The content of the ionic liquids is $0.2 \mathrm{wt} \%$ for those final composites as shown in Table 1 . The ionic liquid content is shown as the mass fraction to the total weight of the final composite composed of sulfur, VGCF, the ionic liquid, and a- $\mathrm{Li}_{3} \mathrm{PS}_{4}$. The first discharge-charge curves of the composite without the ionic liquid are also shown as Fig. 4 (a), for comparison. Those discharge-charge curves of the test cells were obtained under a constant current density of $0.1 \mathrm{mAcm}^{-2}\left(24 \mathrm{mAg}^{-1}\right)$ with a cut-off range of 1.0 to $2.6 \mathrm{~V}$. The first discharge and charge capacities of the final composite without ionic liquid are 950 and $906 \mathrm{mAhg}^{-1}$, respectively. Those capacities are calculated on the weight of sulfur included in the composite that is used as the positive electrode materials of the test cell. Table 2 shows the first discharge and charge capacities of the test cells in which the composites with the five kinds of ionic liquids are used as positive electrode. The capacities of all the composites containing the ionic liquids are larger than that of the composite without the ionic liquids. Those results suggest that the addition of the ionic liquids increases the discharge-charge capacities of the all-solid-state Li-S cells and also improves the utilization of the 
active materials sulfur in the positive electrode composites.

The composite containing [EMI][TFSI] shows the largest capacities, $1270 \mathrm{mAhg}^{-1}$ for the discharge and $1200 \mathrm{mAhg}^{-1}$ for the charge, among the five composites with those ionic liquids. The first discharge-charge capacities of the composite with [EMI][TFSI] are about 1.3 times larger than those of the composite without the ionic liquids.

The addition of those ionic liquids improves the compactibility of the composites and also increases the contact area among sulfur, solid electrolyte and VGCF particles as shown in Fig. 3. Those effects would be easily attained by the addition of low-viscous liquids to the composite powders, because the low-viscous liquids should be dispersed uniformly in the composite. Among the five imidazolium salts that have been tested, [EMI][TFSI] has the lowest viscosity [27]. Hence, the [EMI][TFSI] shows the best performance as the additive to improve the electrochemical performance of the sulfur composite among those five ionic liquids.

Figure 5 shows the discharge-charge curves of the positive electrode composites with various amounts of $[\mathrm{EMI}][\mathrm{TFSI}]$. The amounts of the [EMI][TFSI] in the composites are shown as the mass fraction of the ionic liquid to the total weight of the final composite containing S, VGCF, $\mathrm{a}-\mathrm{Li}_{3} \mathrm{PS}_{4}$ and [EMI][TFSI]. The discharge-charge curves of the composite without the ionic liquid are also shown in the figure for comparison. The capacities of the composites containing $0.2,0.4$ and $2.0 \mathrm{wt} \%$ of [EMI][TFSI] are larger than that of the composite without [EMI][TFSI]. On the other hand, the discharge capacity of the composite with $4.0 \mathrm{wt} \%$ [EMI][TFSI] is only $770 \mathrm{mAhg}^{-1}$ and the capacity is smaller than that of the composite without [EMI][TFSI]. 
Figure 6 shows the [EMI][TFSI] additive amount dependence of the first discharge capacity of the composites. The addition of a small amount of [EMI][TFSI] to the composite causes the increase of the discharge capacity. In the [EMI][TFSI] content range of 0.2 to $2.0 \mathrm{wt} \%$, the capacities of the composites show almost same value of $1270 \mathrm{mAhg}^{-1}$. The further addition of [EMI][TFSI] larger than $3.0 \mathrm{wt} \%$ caused the decrease of the capacity. Those results suggest that the optimum amount of [EMI][TFSI] is in the range of 0.2 to $2.0 \mathrm{wt} \%$ and that the composites containing the optimum amount of [EMI][TFSI] show almost same discharge-charge capacity.

Indeed, those imidazolium salts have ionic conductivity, but do not have lithium-ion conductivity, because we have not added any lithium salt to those ionic liquids. Then the addition of large amount of ionic liquids would form passive layers between sulfur and solid electrolyte particles and the ionic liquid layers would disturb the electrochemical reactions between sulfur and lithium ions. Hence the further addition of the ionic liquids (more than $3.0 \mathrm{wt} \%$ ) caused the decrease in the discharge capacity of the test cells.

On the other hand, the addition of small amounts of the ionic liquids (in the composition range of 0.2 to $2.0 \mathrm{wt} \%$ ) should improve the compactibility of the composite and also increase the contact area between sulfur and solid electrolyte particles as shown in Fig. 3. The small amounts of the ionic liquids are sufficient for the improvement of the compactibility and also for the increase in the contact area. Thus we think that the capacity is almost same in the composition range of 0.2 to $2.0 \mathrm{wt} \%$.

Figure 7 (a) shows the discharge-charge cycle dependence of the discharge capacity of the 
composite containing $0.2 \mathrm{wt} \%$ [EMI][TFSI]. The discharge-charge efficiency of the composite is shown by open circles in Fig. 7 (b). The test cell was cycled with a constant current density of $0.1 \mathrm{mAcm}^{-2}\left(24 \mathrm{mAg}^{-1}\right)$ in the cut-off voltage range of 2.6 to $1.0 \mathrm{~V}$ at $25^{\circ} \mathrm{C}$. The discharge capacity and the discharge-charge efficiency of the composite without [EMI][TFSI] are also shown in the figures by closed circles for comparison. The initial discharge capacities of the composites with and without [EMI][TFSI] are 1270 and $950 \mathrm{mAhg}^{-1}$, respectively. Even after 50 discharge-charge cycles the composite with $0.2 \mathrm{wt} \%$ [EMI][TFSI] retains its capacity of $1230 \mathrm{mAhg}^{-1}$. The capacity retention fraction to the initial capacity is about $97 \%$. The discharge-charge efficiency of the composite with $0.2 \mathrm{wt} \%$ [EMI][TFSI] is almost $100 \%$ over the cycle range. The test cell shows good discharge-charge cycle performance. On the other hand, the composite without [EMI][TFSI] shows $870 \mathrm{mAhg}^{-1}$ as its capacity after 50 cycles. The capacity retention fraction is about $92 \%$. The capacity retention fraction of the composite with $0.2 \mathrm{wt} \%$ [EMI][TFSI] is superior to that of the composite without [EMI][TFSI]. The all-solid-state test cell with the composite containing the small amount (0.2 wt\%) of [EMI][TFSI] exhibits excellent cyclability at the current density of $0.1 \mathrm{mAcm}^{-2}\left(24 \mathrm{mAg}^{-1}\right)$ at room temperature.

\subsection{Discharge-charge properties of the final sulfur-composites at high temperature of $50^{\circ} \mathrm{C}$}

For the Li / S batteries with conventional electrolyte solutions, operating temperature seriously affects on their electrochemical properties, because the solubility of the lithium poly-sulfides $\left(\mathrm{Li}_{2} \mathrm{~S}_{\mathrm{n}}\right)$, which are produced by electrochemical reactions at the positive electrode, is increased with an 
increase in the operating temperature and the dissolved poly-sulfides degrade the $\mathrm{Li} / \mathrm{S}$ battery performance by the polysulfide shuttle mechanism [3, 9-11]. On the other hand, in the all-solid-state $\mathrm{Li} / \mathrm{S}$ battery, the increase in the operating temperature would improve the electrochemical performance of the all-solid-state battery, because the lithium poly-sulfides $\left(\mathrm{Li}_{2} \mathrm{~S}_{\mathrm{n}}\right)$ do not dissolve into the solid electrolyte. Then we investigate the electrochemical properties of the all-solid-state test cell at a high temperature $\left(50^{\circ} \mathrm{C}\right)$.

Figure 8 (a) shows the first discharge-charge curves of the composite containing $0.2 \mathrm{wt} \%$ [EMI][TFSI] at $50^{\circ} \mathrm{C}$. The discharge-charge experiments are performed under two current densities of $0.1 \mathrm{mAcm}^{-2}\left(24 \mathrm{mAg}^{-1}\right)$ and $0.5 \mathrm{mAcm}^{-2}\left(120 \mathrm{mAg}^{-1}\right)$ in the cut-off voltage range of 1.0 to $2.6 \mathrm{~V}$. In the figure, the curves under the current densities of 0.1 and $0.5 \mathrm{mAcm}^{-2}$ are indicated with the solid and dashed lines, respectively. The discharge-charge curves of the test cell without [EMI][TFSI] are also shown in Fig. 8 (b) for comparison. Those composites with and without [EMI][TFSI] show extremely good discharge-charge performance at $50^{\circ} \mathrm{C}$. The first discharge capacity of the composite with $0.2 \mathrm{wt} \%$ [EMI][TFSI] shows $1640 \mathrm{mAhg}^{-1}$ at $0.1 \mathrm{mAcm}^{-2}$, and the capacity is $98 \%$ fraction of the theoretical capacity of sulfur. The composite without [EMI][TFSI] also shows $1605 \mathrm{mAhg}^{-1}$ as the first discharge capacity at $0.1 \mathrm{mAcm}^{-2}$. The first discharge capacities of the composites with and without [EMI][TFSI] are almost the same at a low current density of $0.1 \mathrm{mAcm}^{-2}$ at $50{ }^{\circ} \mathrm{C}$. On the other hand, the first discharge capacities of the composites with and without [EMI][TFSI] are respectively $1331 \mathrm{mAhg}^{-1}$ and $1145 \mathrm{mAhg}^{-1}$ at a high current density of $0.5 \mathrm{mAcm}^{-2}$. The capacity of the composite with [EMI][TFSI] is larger than 
that of the composite without the ionic liquid. Those results suggest that the addition of the [EMI][TFSI] to the composite is effective to improve the high current discharge properties of the composite.

The discharge-charge cycle dependence of the discharge capacity of the composite with $0.2 \mathrm{wt} \%$ [EMI][TFSI] is shown in Fig. 9 (a) by open circles. The discharge-charge cycling test has been carried out under a high current density of $0.5 \mathrm{mAcm}^{-2}\left(120 \mathrm{mAg}^{-1}\right)$ at $50^{\circ} \mathrm{C}$. The discharge capacity of the composite without [EMI][TFSI] is also shown in the figure by closed circles. The discharge-charge efficiencies of the test cells are also shown in Fig. 9 (b). The first discharge capacity of the composite with $0.2 \mathrm{wt} \%$ [EMI][TFSI] is $1331 \mathrm{mAhg}^{-1}$. The capacity retention of the composite with $0.2 \mathrm{wt} \%$ [EMI][TFSI] is $86 \%$ after 100 cycles.

On the other hand, the first discharge capacity of the composite without [EMI][TFSI] is $1145 \mathrm{mAhg}^{-1}$. The discharge capacity decreases with an increase in the discharge-charge cycle numbers. The discharge capacity of the composite without [EMI][TFSI] shows $841 \mathrm{mAhg}^{-1}$ after 50 cycles and then reaches to $499 \mathrm{mAhg}^{-1}$ after 100 cycles. The capacity retention of the composite without [EMI][TFSI] is only $44 \%$ after 100 cycles. The discharge-charge efficiencies of the test cells with and without [EMI][TFSI] are almost unity over the cycle range. The composite with $0.2 \mathrm{wt} \%$ [EMI][TFSI] shows excellent discharge-charge cycle performance at $50{ }^{\circ} \mathrm{C}$. Those results suggest that the addition of small amount of [EMI][TFSI] to the composite is extremely effective on the discharge-charge cycle performance of the all-solid-state test cells at $50^{\circ} \mathrm{C}$.

The impedance of the test cells before and after the discharge-charge cycle tests was measured at 
$0.01 \mathrm{~Hz}$. The measurements were carried out for the test cells after charging up to $2.6 \mathrm{~V}$ at $50{ }^{\circ} \mathrm{C}$.

The resistance of the composite without the ionic liquid was $358 \Omega \mathrm{cm}^{2}$ at $0.01 \mathrm{~Hz}$ after the first charge. The resistance was increased with the discharge-charge cycling and reached to $538 \Omega \mathrm{cm}^{2}$ after 50 cycles. The increase of the resistance during 50 cycles was $170 \Omega \mathrm{cm}^{2}$ for the composite without the ionic liquid.

On the other hand, the resistance of the composite with $0.2 \mathrm{wt} \%$ [EMI][TFSI] after the first charge is $311 \Omega \mathrm{cm}^{2}$ at $0.01 \mathrm{~Hz}$. The resistance was also increased with the discharge-charge cycling and reached to $396 \Omega \mathrm{cm}^{2}$ after 50 cycles. The resistance increase of the test cell with the [EMI][TFSI] was only $85 \Omega \mathrm{cm}^{2}$ during cycling. The increase in the resistance of the test cell with $[E M I][T F S I]$ is smaller than that of the cell without the ionic liquid. Thus, the test cell with $0.2 \mathrm{wt} \%$ [EMI][TFSI] shows superior discharge-charge cycle performance to that of the cell without the ionic liquid.

During the discharge reaction of sulfur electrode in Li / S battery, elemental sulfur is reduced into polysulfide $\left(\mathrm{Li}_{2} \mathrm{~S}_{\mathrm{n}}\right)$, and then the poly-sulfides form $\mathrm{Li}_{2} \mathrm{~S}$ as the final product via electrochemical reductions. The electrochemical reactions progress at the three-phase interface regions among the active materials S, electronic conductor VGCF, and solid electrolyte $\mathrm{a}-\mathrm{Li}_{3} \mathrm{PS}_{4}$ during the discharge of the test cells. Those poly-sulfides and $\mathrm{Li}_{2} \mathrm{~S}$ are precipitated in the interface regions, which are active points for the reaction, during the discharge reaction. The precipitated $\mathrm{Li}_{2} \mathrm{~S}$ would form passivation layers at the interface between the electronic conductor VGCF and the solid electrolyte a- $-\mathrm{Li}_{3} \mathrm{PS}_{4}$, because the electronic and ionic conductivity of the deposited $\mathrm{Li}_{2} \mathrm{~S}$ is poor. Even 
when the battery is fully charged, the $\mathrm{Li}_{2} \mathrm{~S}$ passivation layers would still remain in the composite.

This passivation layer leads not only to capacity loss and also to high internal resistance of the battery. When the battery works under a high current density, the effect of the resistive $\mathrm{Li}_{2} \mathrm{~S}$ layer should become significant. Then we suppose that the capacity of the composite without the ionic liquid decreased with an increase in cycle numbers, when the battery works at a high current density of $0.5 \mathrm{mAcm}^{-2}$.

The lithium sulfide $\left(\mathrm{Li}_{2} \mathrm{~S}\right)$ and the lithium poly-sulfides $\left(\mathrm{Li}_{2} \mathrm{~S}_{\mathrm{n}}\right)$ that are products during the discharge would slightly dissolve in the ionic liquid [EMI][TFSI], which is added to the composite electrodes. The dissolution of the lithium sulfide $\left(\mathrm{Li}_{2} \mathrm{~S}\right)$ and the lithium poly-sulfides would be helpful to remove the passivation layers from the active interfaces at which the electrochemical reaction would occur in the composite electrode of the test cells. Indeed the solubilities of the lithium sulfide $\left(\mathrm{Li}_{2} \mathrm{~S}\right)$ and of the lithium poly-sulfides into the ionic liquid would be very small. However, when the dissolution-deposition rates of the lithium sulfide $\left(\mathrm{Li}_{2} \mathrm{~S}\right)$ and the lithium poly-sulfides are rapid, the ionic liquid should be effective to remove the passivation layers from the interfacial regions, which are active points for electrochemical reactions, and to progress the electrochemical reactions in the composite. The addition of small amounts of the ionic liquid would be also helpful to increase the uniformity in the composite.

\section{Conclusion}

The additive effects of ionic liquids on discharge-charge properties of the sulfur-VGCF-a-Li $\mathrm{PS}_{4}$ 
composites were investigated in order to improve the performance of the composites as positive electrode materials for all-solid-state $\mathrm{Li} / \mathrm{S}$ battery. The five kinds of ionic liquids, 1-ethyl-3methyl-imidazolium bis(trifluoromethane-sulfonyl)imide [EMI][TFSI], 1-ethyl-3-methylimidazolium tetrafluoroborate [EMI][BF 4 ], 1-buthyl-3-methyl-imidazolium bis(trifluoromethanesulfonyl) imide [BMI][TFSI], 1-buthyl-3-methyl-imidazolium tetrafluoroborate [BMI][BF 4 , and 1-buthyl-3-methyl-imidazolium iodide [BMI][I], were used as the additives to the composite electrode. Among the ionic liquids, [EMI][TFSI] showed most effective to improve the discharge- charge property of the sulfur composite electrode. When the discharge-charge test was performed under a constant current density of $0.1 \mathrm{mAcm}^{-2}$, the all-solid-state cell with the composite containing $0.2 \mathrm{wt} \%$ [EMI][TFSI] showed the large initial specific capacity of $1270 \mathrm{mAhg}^{-1}$, and retained the large capacity of $1230 \mathrm{mAhg}^{-1}$ even after 50 cycles at $25^{\circ} \mathrm{C}$. When the discharge-charge cycle test was performed under a high current density of $0.5 \mathrm{mAcm}^{-2}\left(120 \mathrm{mAg}^{-1}\right)$ at a high temperature of $50{ }^{\circ} \mathrm{C}$, the composite with $0.2 \mathrm{wt} \%$ [EMI][TFSI] showed a large specific capacity of $1331 \mathrm{mAhg}^{-1}$ as the first discharge capacity. Furthermore, the composite with $0.2 \mathrm{wt} \%$ [EMI][TFSI] retained the large capacity more than $1150 \mathrm{mAhg}^{-1}$ even after 100 cycles. The composite without [EMI][TFSI] also showed the high initial discharge capacity of $1145 \mathrm{mAhg}^{-1}$ under a high current density of $0.5 \mathrm{mAcm}^{-2}$ at $50{ }^{\circ} \mathrm{C}$. However, the capacity of the composite without [EMI][TFSI] decreased with an increase in the cycle number and reached only $499 \mathrm{mAhg}^{-1}$ after 100 cycles. Those results suggest that the addition of small amount of [EMI][TFSI] to the sulfur composites is very effective to improve the discharge-charge performance of the sulfur 
composites as positive electrode materials for all-solid-state batteries with inorganic solid electrolytes.

\section{Acknowledgment}

This work was partly supported by the Advanced Low Carbon Technology Research and Development program (ALCA) of the Japan Science and Technology Agency (JST). 


\section{Reference:}

[1] P. G. Bruce, S. T. Freunberger, L. J. Hardwick, and J. -M. Tarascon. Nat. Mater., $\underline{11}$ (2012) 19.

[2] C. Daniel and J. O. Besenhard eds., "Handbook of Battery Materials 2nd, ” Wiley-VCH Verlag \& KGaA, Germany (2012).

[3] R. D. Rauh, K. M. Abraham, G. F. Pearson, J. K. Surprenant, and S. B. Brummer, J. Electorchem. Soc., 126 (1979) 523.

[4] B. L. Ellis, K. T. Lee, and L. F. Nazar, Chem. Mater., $2 \underline{2}$ (2012) 691.

[5] Y. V. Mikhaylik and J. R. Akridge, J. Electerochem. Soc., 151 (2004) A1969.

[6] E. Peled, A. Gorenshtein, M. Segal, and Y. Sternberg, J. Power Sources, 26 (1989) 269.

[7] D. Peramunage and S. Licht, Science, $\underline{261}$ (1993) 1029.

[8] X. Ji and L. F. Nazar, J. Mater. Chem., $\underline{20}$ (2010) 9821.

[9] E. Peled, Y. Sternberg, A. Gorenshtein, and Y. Lavi, J. Electrochem. Soc., 136 (1989) 1621.

[10] S. E. Cheon, K. S. Ko, J. H. Cho, S. W. Kim, E. Y. Chin, and H. T. Kim, J. Electrochem. Soc., $\underline{150}$ (2003) A796.

[11] B. M. L. Rao and J. A. Shrophire, J. Electrochem. Soc. 128 (1981) 942.

[12] A. Hayashi, T. Ohtomo, F. Mizuno, K. Tadanaga, and M. Tatsumisago, Electrochem. Comm., $\underline{\mathbf{5}}$ (2003) 701.

[13] M. Nagao, A. Hayashi, and M. Tatsumisago, J. Mater. Chem., 22 (2012) 10015.

[14] N. Machida, K. Kobayashi, Y. Nishikawa, and T. Shigematsu, Solid State Ionics, 175 (2004) 247.

[15] N. Machida and T. Shigematsu, Chem. Lett., $\underline{33}$ (2004) 376.

[16] M. Nagao, Y. Imade, H. Narisawa, T. Kobayashi, R. Watanabe, T. Yokoi, T. Tatsumi, and R. Kanno, J. Power Sources, 222 (2013) 237. 
[17] M. Nagao, Y. Imade, H. Narisawa, H. Narisawa, R. Watanabe, T. Yokoi,

T. Tatsumi, and R. Kanno, J. Power Sources $\underline{243}$ (2013) 60.

[18] S. Kinoshita, K. Okuda, N. Machida, M. Naito, and T. Shigematsu, Solid State Ionics, $\underline{\mathbf{2 5 6}}$ (2014) 97.

[19] A. Hayashi, H. Hama, H. Morimoto, M. Tatsumisago, and T. Minami, J. Am. Ceram. Soc., $\underline{\mathbf{8 4}}$ (2001) 477.

[20] A. Hayashi, S. Hama, T. Minami, and M. Tatsumisago, Electrochem. Comm., $\underline{\mathbf{5}}$ (2003) 111.

[21] M. Nagao, A. Hayashi, and T. Tatsumisago, Electrochim. Acta, $\underline{\mathbf{5 6}}$ (2011) 6055.

[22] M. Agostini, Y. Aihara, T. Yamada, B. Scrosati, and J. Hassoun, Solid State Ionics, $\underline{244}$ (2013) 48.

[23] M. Nagao, A. Hayashi, M. Tatsumisago, Energy Tech. $\underline{1}$ (2013) 186.

[24] P. Bonhôte, A. -P. Dias, N. Papageorgiou, K. Kalyanasundaram, and M. Grätzel, Inorg. Chem., $\underline{35}$ (1996) 1168.

[25] E. A. Turner, C. C. Pye, and R. D. Singer, J. Phys. Chem. A, 107 (2003) 2277.

[26] S. Tsuzuki, H. Tokuda, K. Hayamizu, and M. Watanabe, J. Phys. Chem. B, $\underline{109}$ (2005) 16474.

[27] M. Atilhan, J. Jacquemin, D. Rooney, M. Khraisheh, and S. Aparicio. Ind. Eng. Chem. Res., $\underline{52}$ (2013) 16774.

[28] T. Welton, Chem. Rev. $\underline{99}$ (2008) 229.

[29] P. Wasserscheid, W. Keim, Angew. Chem. Int. Ed., $\underline{39}$ (2000) 3772.

[30] K. R. Seddon, Nat. Mater. $\underline{2}$ (2003) 363. 
[31] S. Seki, N. Serizawa, K. Takei, K. Dokko, M. Watanabe, J. Power Sources, $\underline{\mathbf{2 4 3}}$ (2013) 323.

[32] K. Ueno, J. -W. Park, A. Ymazaki, T. Mandai, N. Tachikawa, K. Dokko, M. Watanabe, J. Phys. Chem. C, $\underline{117}$ (2013) 20509.

[33] J. -W. Park, K. Ueno, N. Tachikawa, K. Dokko, M. Watanabe, J. Phys. Chem. C, 117 (2013) 20531.

[34] M. Armand, F. Endres, D. R. MacFarlane, H. Ohno, B. Scrosati, Nat. Mater., 8 (2009) 621.

[35] J. -W. Park, K. Yamauchi, E. Takashima, N. Tachikawa, K. Ueno, K. Dokko, and M. Watanabe, J. Phys. Chem. C, $\underline{117}$ (2013) 4431.

[36] N. Machida, H. Yamamoto, S. Asano, and T. Shigematsu, Solid State Ionics, $\underline{176}$ (2005) 473.

[37] Y. Hashimoto, N. Machida, and T. Shigematsu, Solid State Ionics, $\underline{175}$ (2004) 177.

[38] R. Tamori, N. Machida, and T. Shigematsu, J. Jpn. Soc. Powder and Powder Metallurgy, $\underline{48}$ (2001) 267. 


\section{Figure Captions:}

Fig. 1 A schematic diagram of the preparation procedure of the composites composed of sulfur, VGCF, ionic liquids, and amorphous $\mathrm{Li}_{3} \mathrm{PS}_{4}$.

Fig. 2 The photographs of the intermediate composite powders and of the pellets obtained from the composites powders, (a) without [EMI][TFSI] and (b) with $5.0 \mathrm{wt} \%$ [EMI][TFSI]. (For the sample the [EMI][TFSI] mass fraction to the total weight of the final composite composed of sulfur, VGCF, [EMI][TFSI] and $\mathrm{Li}_{3} \mathrm{PS}_{4}$ is $2.0 \mathrm{wt} \%$.)

Fig.3 SEM images of the sulfur-VGCF-solid electrolyte composites with and without [EMI][TFSI]: (a) and (b) are the images of the composites without [EMI][TFSI]. (c) and (d) are the images of the composites with $0.4 \mathrm{wt} \%$ [EMI][TFSI].

Fig. 4 The first discharge-charge curves of the all-solid-state test cells using the sulfur-VGCF- $\mathrm{Li}_{3} \mathrm{PS}_{4}$ composites (a) without ionic liquids and with the ionic liquids, (b) [EMI][TFSI], (c) [EMI][BF $]$, (d) [BMI][TFSI], (e) [BMI][BF 4 , and (f) [BMI][I].

Fig.5 The first discharge-charge curves of the all-solid-state cells using (a) the sulfur-VGCF-Li $\mathrm{PS}_{4}$ composite without ionic liquids and using the composites containing various amounts of [EMI][TFSI]; $\quad$ (b) $0.2 \mathrm{wt} \%$, (c) $0.4 \mathrm{wt} \%$, (d) $2.0 \mathrm{wt} \%$ and 
(e) $4.0 \mathrm{wt} \%$.

Fig. 6 The relation between the first discharge capacity and the amounts of [EMI][TFSI] in the final composites composed of sulfur, VGCF, [EMI][TFSI] and $\mathrm{Li}_{3} \mathrm{PS}_{4}$.

Fig.7 (a) The discharge-charge cycle dependence of the discharge capacities of the composites with $0.2 \mathrm{wt} \%$ [EMI][TFSI] (open circles) and without [EMI][TFSI] (closed circles). The cycle tests were carried out under a constant current density of $0.1 \mathrm{mAcm}^{-2}$ $\left(24 \mathrm{mAg}^{-1}\right)$ at $25^{\circ} \mathrm{C} . \quad$ (b) the cycle dependence of the discharge-charge efficiencies of the composites with $0.2 \mathrm{wt} \%$ [EMI][TFSI] (open circles) and without [EMI][TFSI] (closed circles).

Fig. 8 The first discharge-charge curves of the all-solid-state cells using the sulfur-VGCF-Li $\mathrm{PS}_{4}$ composites (a) containing $0.2 \mathrm{wt} \%$ [EMI][TFSI] and (b) without ionic liquids. The all-solid-state cells were tested under two current densities of $0.1 \mathrm{mAcm}^{-2}\left(24 \mathrm{mAg}^{-1}\right)$ and $0.5 \mathrm{mAcm}^{-2}\left(120 \mathrm{mAg}^{-1}\right)$ at $50{ }^{\circ} \mathrm{C}$.

Fig. 9 (a) the discharge-charge cycle dependences of the discharge capacities of the positive electrode composites with $0.2 \mathrm{wt} \%$ [EMI][TFSI] (open circles) and without [EMI][TFSI]. The cycle test was carried out under a constant current density of $0.5 \mathrm{mAcm}^{-2}\left(120 \mathrm{mAg}^{-1}\right)$ 
at $50^{\circ} \mathrm{C}$. (b) the cycle dependence of the discharge-charge efficiencies of the test cells using the composites with $0.2 \mathrm{wt} \%$ [EMI][TFSI] (open circles) and without [EMI][TFSI]. 
Table 1 The weight ratios of sulfur, VGCF, solid electrolyte and ionic liquid of the obtained final composites.

\begin{tabular}{|c|c|c|c|}
\hline ionic liquid & sulfur & VGCF & solid electrolyte \\
\hline [wt\%] & [wt $\%]$ & [wt $\%]$ & [wt $\%]$ \\
\hline 0 & 30.0 & 10.0 & 60.0 \\
\hline 0.2 & 29.9 & 9.9 & 60.0 \\
\hline 0.4 & 29.7 & 9.9 & 60.0 \\
\hline 1.2 & 29.1 & 9.7 & 60.0 \\
\hline 2.0 & 28.5 & 9.5 & 60.0 \\
\hline 2.8 & 27.9 & 9.3 & 60.0 \\
\hline 4.0 & 27.0 & 9.0 & 60.0 \\
\hline
\end{tabular}

Table 1 S. Kinoshita et. al. 
Table 2 The first discharge-charge capacities of the all-solid-state test cells with the composites composed of $\mathrm{S}$, VGCF, ionic liquid, and $\mathrm{a}_{-} \mathrm{Li}_{3} \mathrm{PS}_{4}$. Five kinds of ionic liquids 1-ethyl-3-methyl-imidazolium bis (trifluoromethane-sulfonyl) imide [EMI][TFSI], 1-ethyl-3-methylimidazolium tetrafluoroborate [EMI] [BF 4 , 1-buthyl-3-methyl-imidazolium bis (trifluoromethanesulfonyl) imide [BMI][TFSI], 1-buthyl-3-methyl-imidazolium tetrafluoroborate [BMI][BF $\left.\mathrm{BF}_{4}\right]$ and 1-buthyl-3-methyl-imidazolium iodide [BMI][I] were tested as additive ionic liquids. The positive electrode composites were composed of sulfur (29.9 wt\%), VGCF (9.9 wt\%), ionic liquid $(0.2 \mathrm{wt} \%)$, and $\mathrm{a}-\mathrm{Li}_{3} \mathrm{PS}_{4}(60 \mathrm{wt} \%)$.

\begin{tabular}{|c|c|c|}
\hline \multirow[t]{2}{*}{ Ionic liquid } & discharge capacity & charge capacity \\
\hline & {$\left[\mathrm{mAhg}^{-1}\right]$} & {$\left[\mathrm{mAhg}^{-1}\right]$} \\
\hline (a) without ionic liquid & 950 & 906 \\
\hline (b)[EMI][TFSI] & 1260 & 1200 \\
\hline (c) $[\mathrm{EMI}]\left[\mathrm{BF}_{4}\right]$ & 1166 & 1099 \\
\hline (d)[BMI][TFSI] & 1190 & 1160 \\
\hline (e) $[\mathrm{BMI}]\left[\mathrm{BF}_{4}\right]$ & 1002 & 960 \\
\hline (f) $[\mathrm{BMI}][\mathrm{I}]$ & 980 & 920 \\
\hline
\end{tabular}

Table 2 S. Kinoshita et. al. 

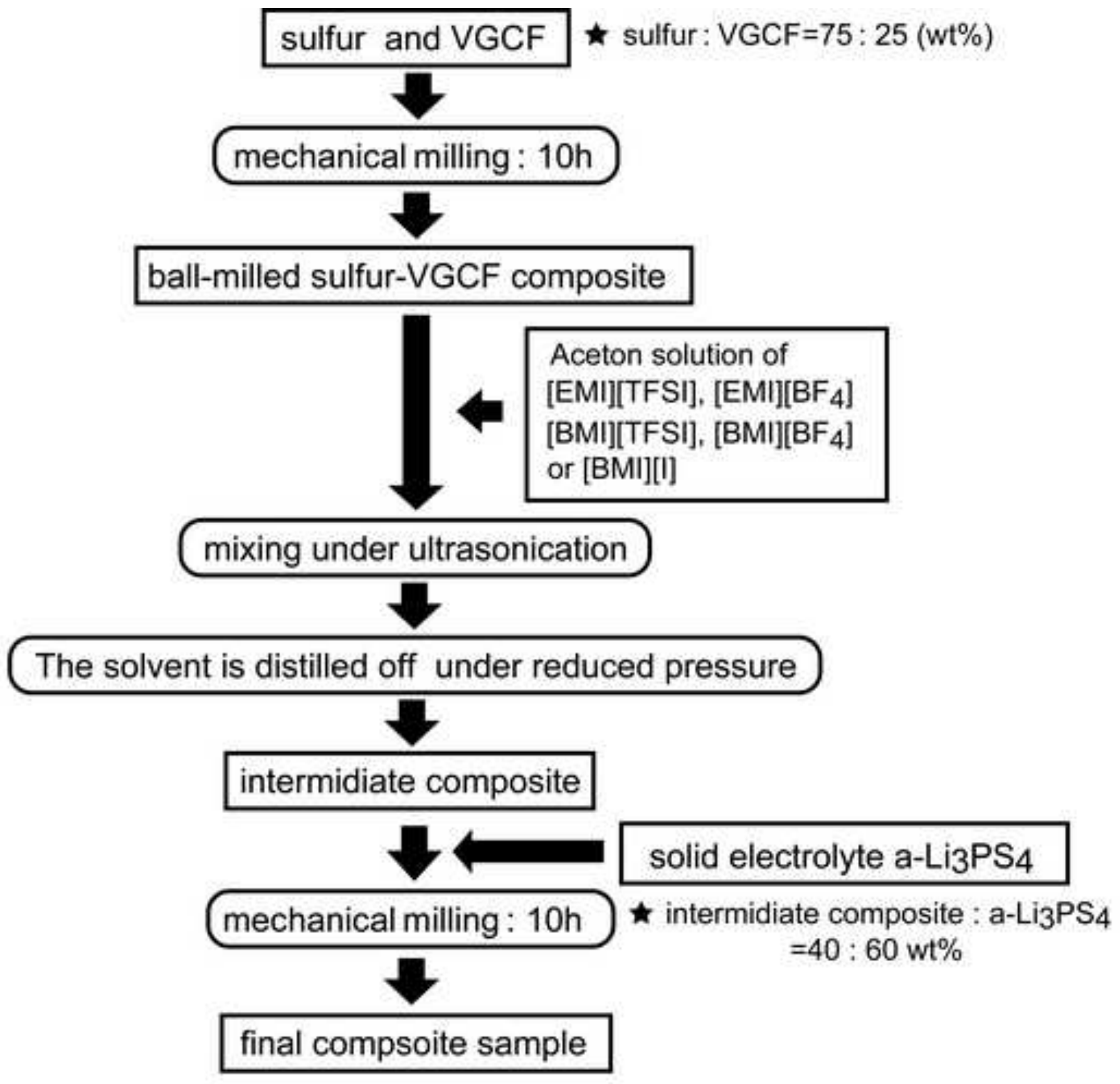

Fig. 1 S. Kinoshita et. al., 

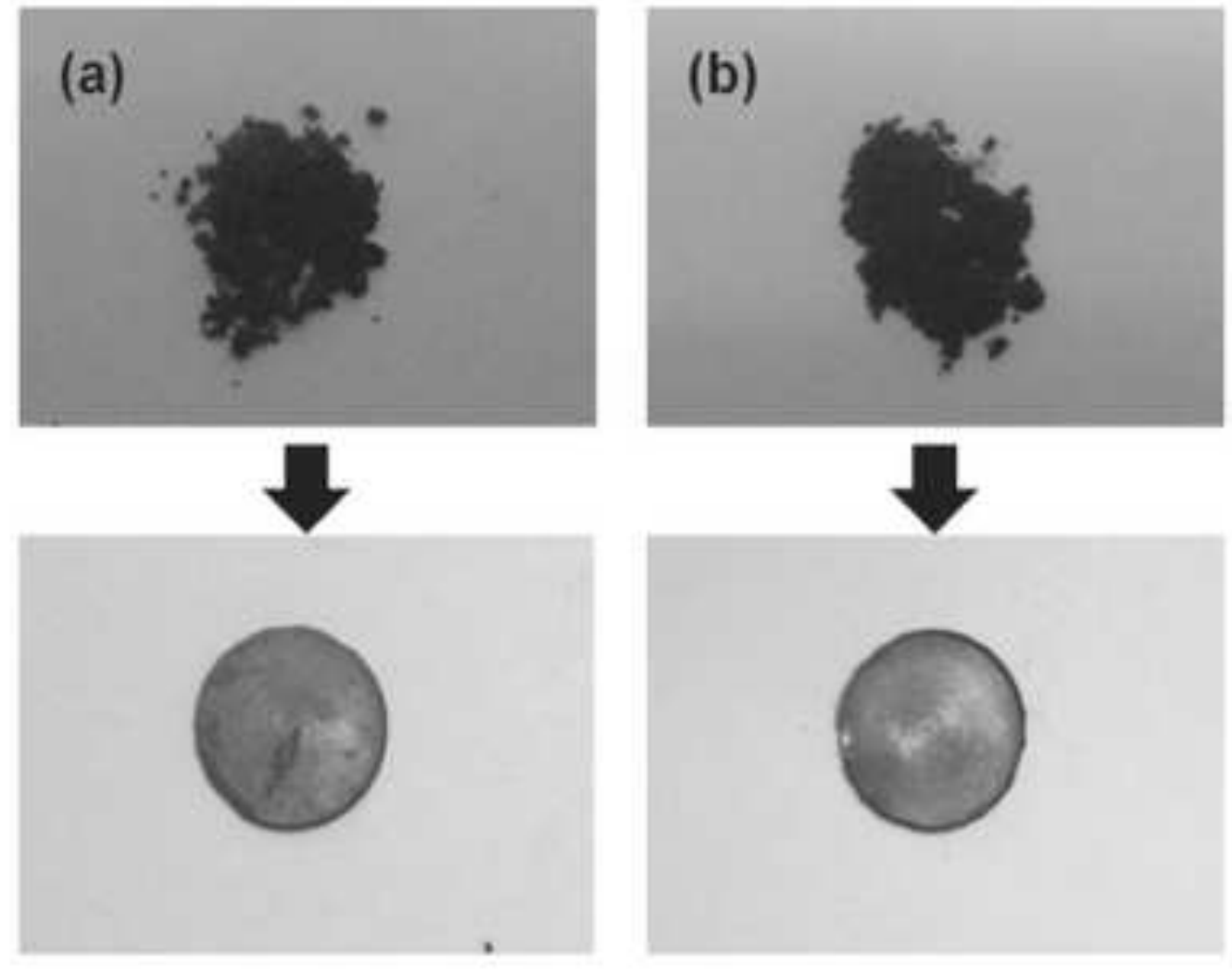

Fig. 2 S. Kinoshita et. al., 

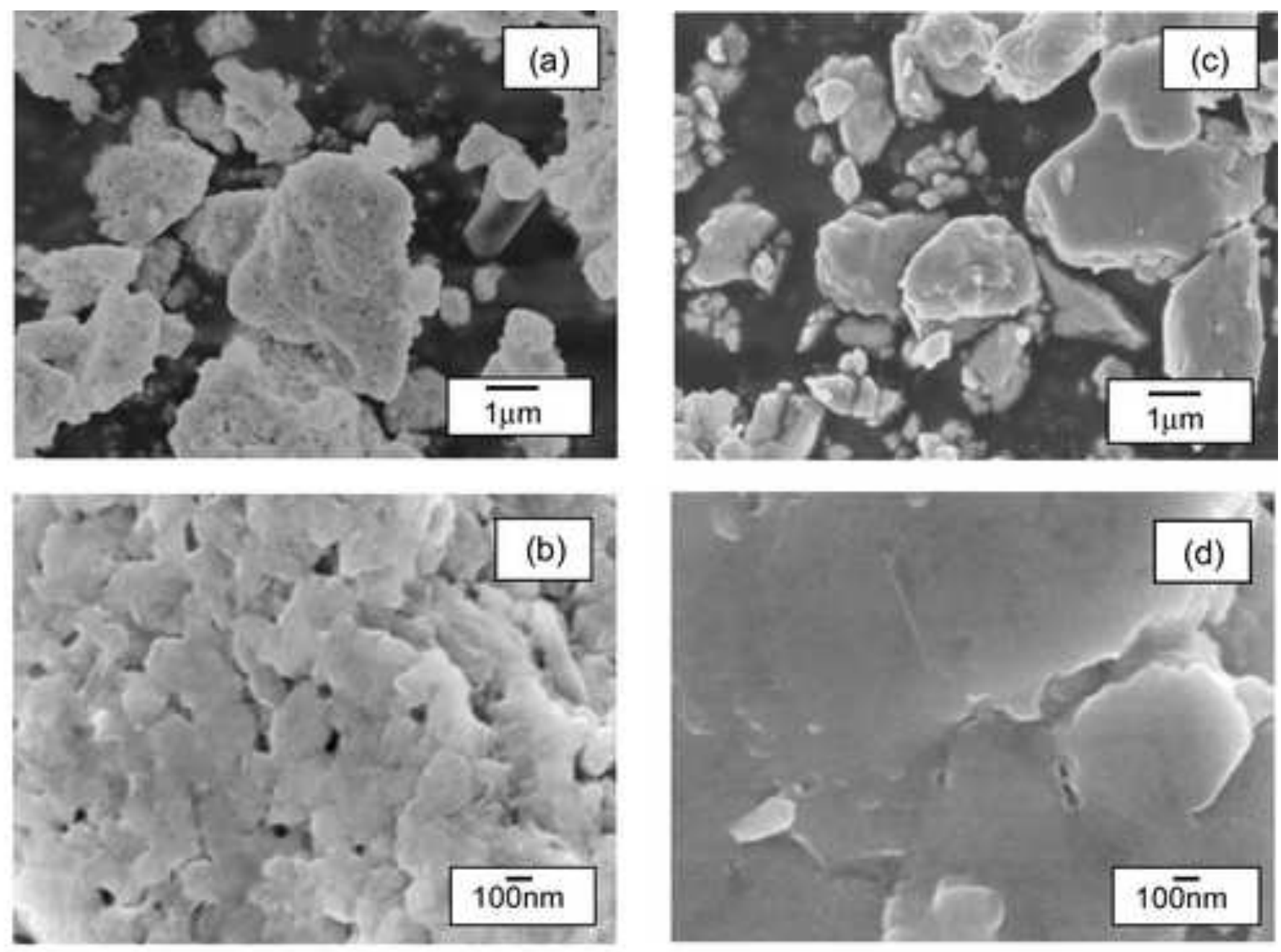

Fig. 3 S. Kinoshita et. al., 


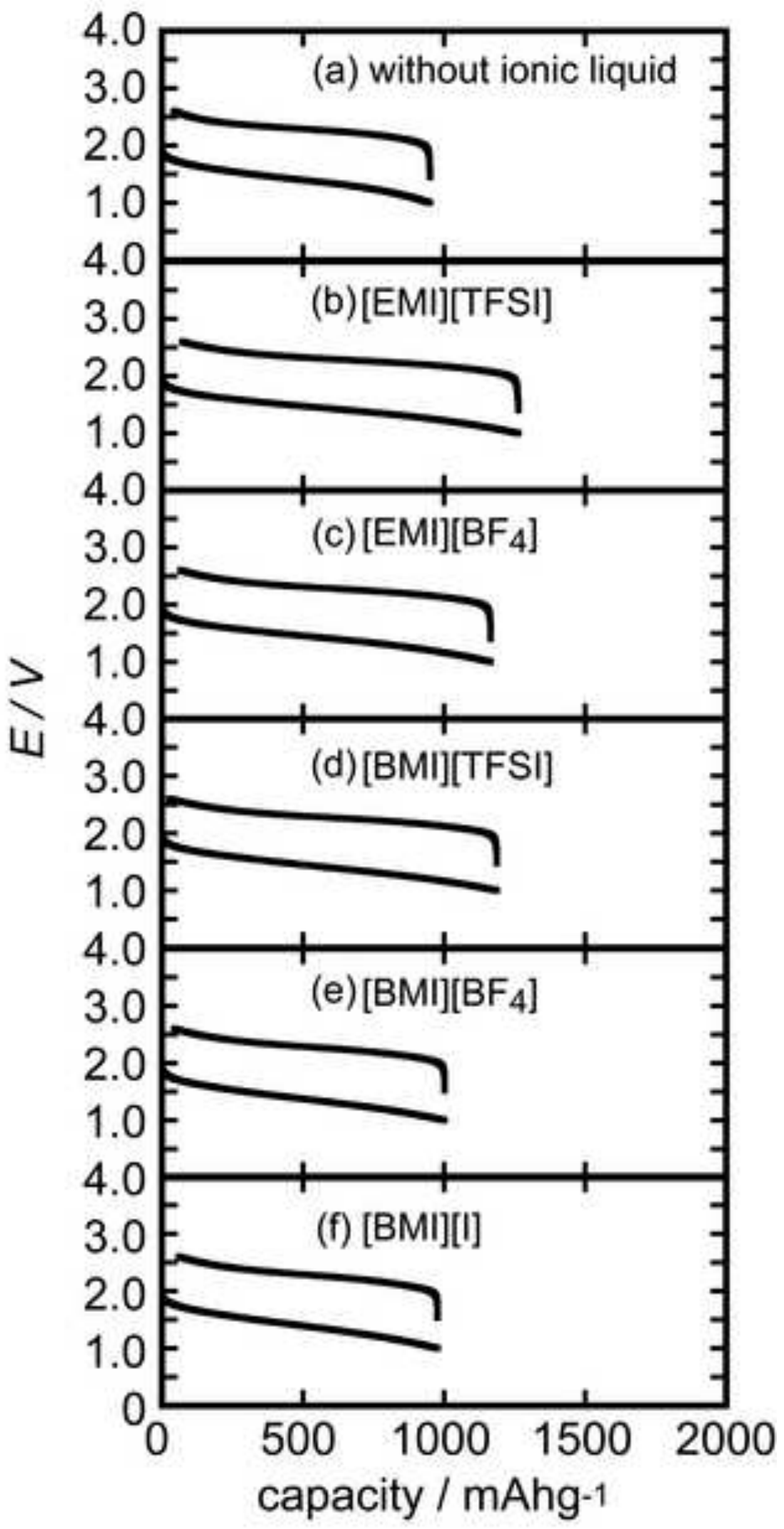

Fig. 4 S. Kinoshita et. al., 


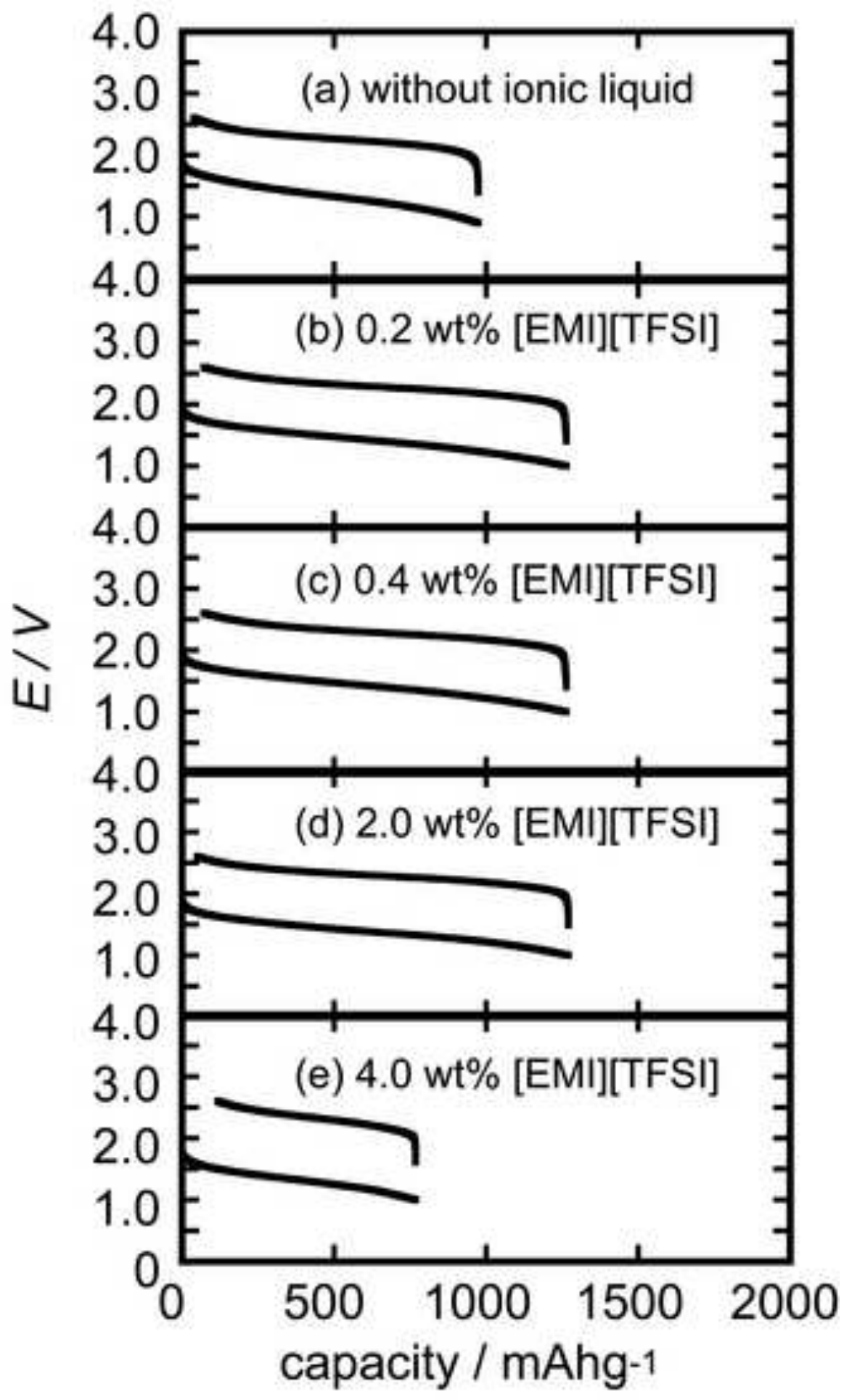

Fig. 5 S. Kinoshita et. al., 


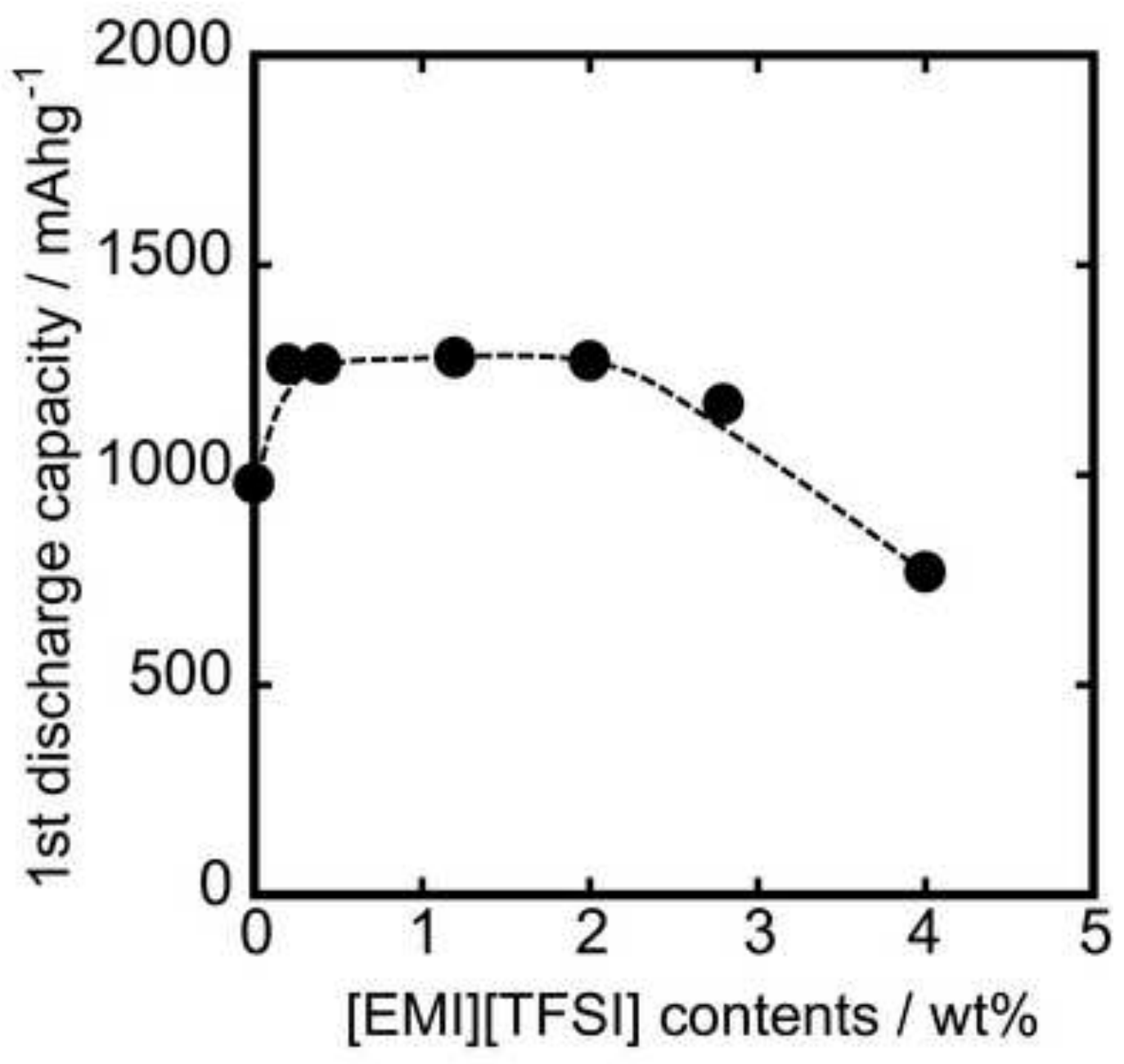

Fig. 6 S. Kinoshita et. al., 

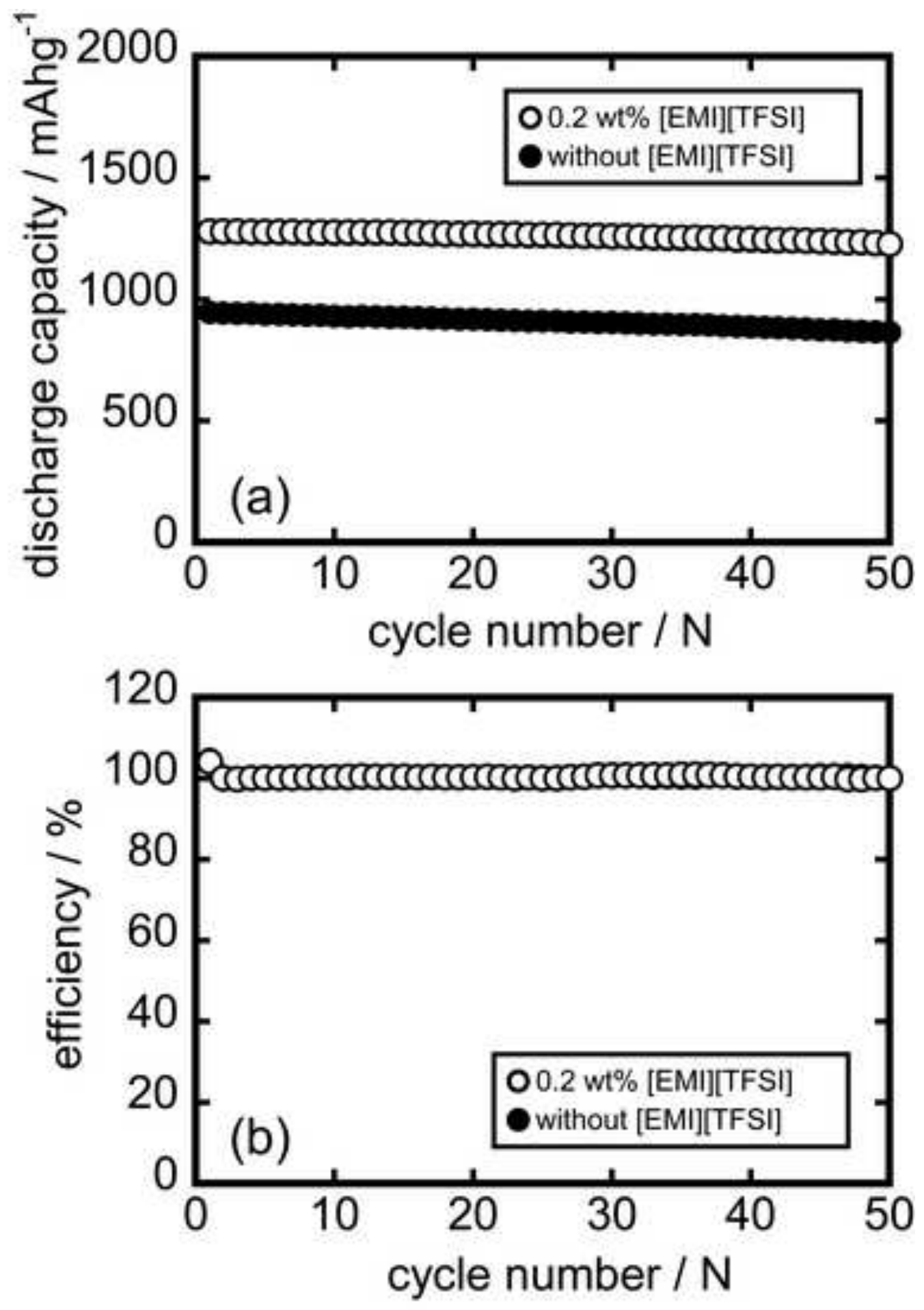

Fig. 7 S. Kinoshita et. al., 


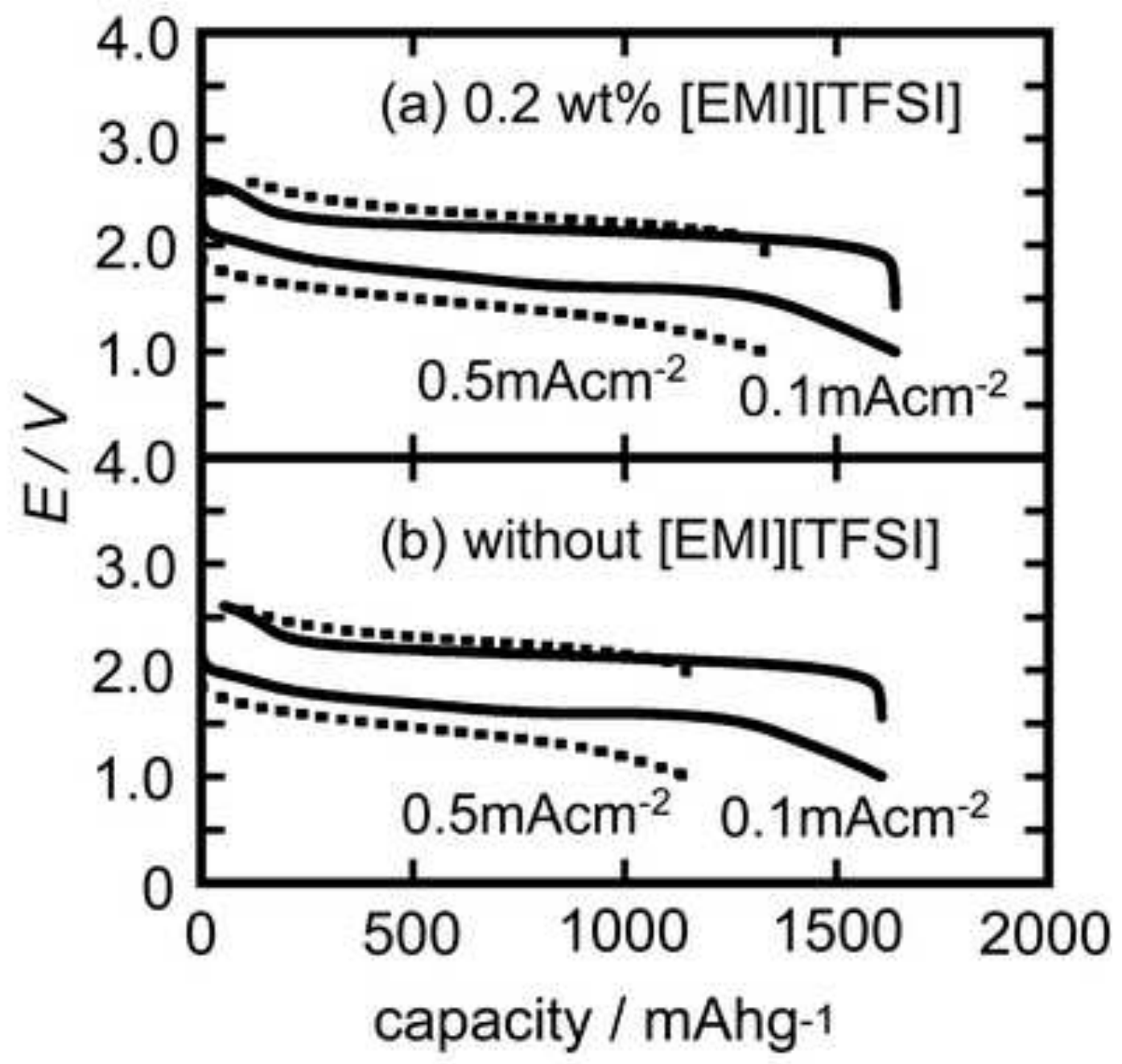

Fig. 8 S. Kinoshita et. al., 

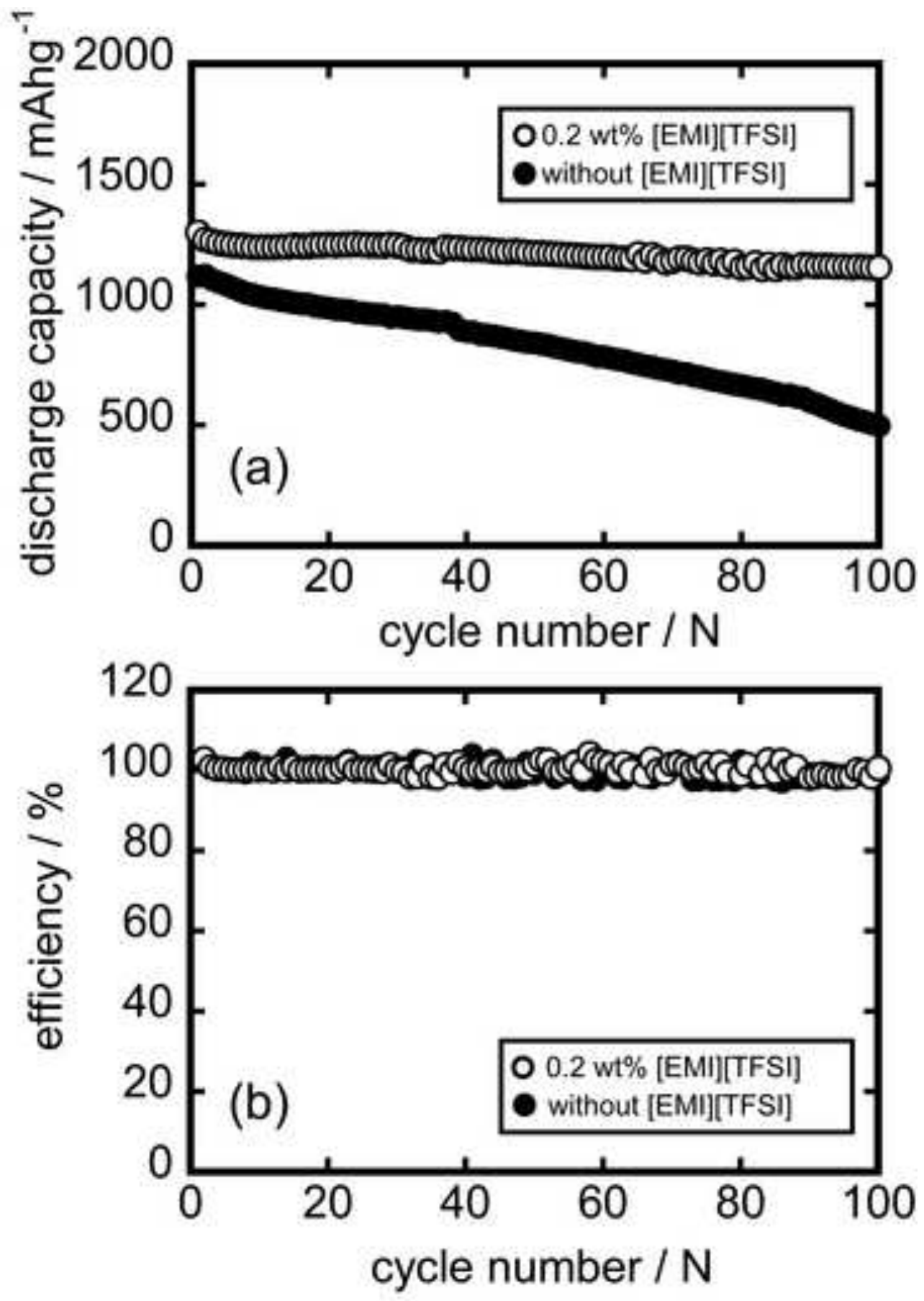

Fig. 9 S. Kinoshita et. al., 